\title{
KOMUNIKASI PARTISIPATIF DAN JARINGAN KOMUNIKASI DALAM MEMBANGUN AKSI KOLEKTIF PERKUMPULAN PETANI PENGGUNA AIR (P3A) DI DAERAH IRIGASI PAPAH
}

\section{The Participatory Communication and Communication Network to Build Collective Action on Farmer Water Users Associations in Irrigation Area Papah}

\author{
Rizki Mila Amalia ${ }^{1}$, Sarwititi Sarwoprasodjo ${ }^{2}$, Resfa Fitri $^{3}$ \\ ${ }^{1}$ Program Studi Komunikasi Pembangunan Pertanian dan Pedesaan, FEMA IPB \\ ${ }^{2}$ Departemen Komunikasi Pembangunan Pertanian dan Pedesaan \\ ${ }^{3}$ Seksi Pengembangan Kelembagaan, Direktorat Pengelolaan Air Irigasi, \\ Kementerian Pertanian \\ e-mail: rizkimilaamaliahamim@gmail.com
}

\begin{abstract}
The research background is government's goal to achieve food self-sufficiency, but it is difficult to increase food production because of the water scarcity due to climatic anomalies, presumably may affect communication activities and collective action of groups that manages irrigation system at the grassroots level. The objectives of this research are to analyze the level of participatory communication and communication network in group, and also to analyze its impact to collective action rates. Research was conducted on Farmer Water Users Associations in irrigation area Papah, began in March to April 2016. The approach taken with qualitative method and designed as a census on the character of descriptive correlation. The result showed that good ability on dialogue and high chance of expressed aspirations, did not necessarily made the participation of members in collective action becomes high. Collective action find in P3A with difficulty in obtaining water for their farming activities in the dry season. Network density GP3A Papah is 1,4 percent, it means low interaction occurs among actors. Collective action would decrease in P3A with high-density network, because in these conditions would create a closed network and occurred high homogeneity of the information so new informations and innovations difficult to enter the network.
\end{abstract}

Keywords : aspiration, collective action, communication network, dialogue

\begin{abstract}
ABSTRAK
Latar belakang penelitian ini adalah pencapaian tujuan swasembada pangan pemerintah, tetapi kesulitan peningkatan produksi makanan karena kelangkaan air akibat anomali, rupanya mempengaruhi aktivitas komunikasi dan aksi kolektif dari kelompok yang mengelola sistem irigasi pada tingkat akar rumput. Tujuan penelitian ini adalah menganalisa tingkat komunikasi partisipatoris dan jaringan komunikasi dalam kelompok, dan juga menganalisa dampaknya kepada aksi kolektif. Penelitian dilaksanakan di Perkumpulan Petani Pengguna Air (P3A) di wilayah irigasi Papah, mulai pada bulan Maret hingga April 2016. Pendekatan yang digunakan adalah metode kualitatif dan dilakukan sensus untuk melihat hubungan deskripsi karakter. Hasil menunjukan bahwa kemampuan dialog yang baik dan kesempatan mengekspresikan aspirasi, tidak dapat memastikan bahwa partisipasi anggota pada aksi kolektif menjadi tinggi. Aksi kolektif yang terjadi di P3A dengan kesulitan mendapatkan air untuk kegiatan pertanian di musim kering. Kepadatan jaringan P3A Papah adalah 1,4 persen, artinya terjadi interaksi yang rendah di antara aktor. Aksi kolektif akan menurun dalam
\end{abstract}


kepadatan jaringan yang tinggi, karena pada kondisi tersebut akan membentuk jaringan yang dekat dan memunculkan keseragaman (homogenitas) informasi sehingga informasi dan inovasi baru akan sulit untuk masuk ke jaringan.

Kata Kunci : aspirasi, aksi kolektif, jaringan komunikasi, dialog

\section{PENDAHULUAN}

Target mencapai kedaulatan pangan dengan swasembada pangan muncul sebagai salah satu program kerja pada masa jabatan Presiden Jokowi. Produktivitas hasil pertanian, terutama tanaman padi, tentunya tidak terlepas dari faktor ketersediaan air. Hasan (dalam Sutrisno dan Heryani 2013) mengatakan dalam mengelola air untuk ketahanan pangan harus memperhitungkan aspek water security. Untuk mencapai water security diperlukan adanya investasi nasional dalam pengembangan sumber daya, baik untuk infrastruktur maupun kelembagaan. Indonesia memiliki lembaga di tingkat grassroot yang bergerak di bidang pengelolaan air irigasi untuk pertanian, yaitu Perkumpulan Petani Pengguna air (P3A).

Tujuan meningkatkan produksi pangan ini masih dihadapkan pada berbagai kendala, salah satunya adalah kelangkaan air (water scarcity) akibat adanya penurunan curah hujan karena fenomena iklim El Nino (Hadi, Irawan dalam Rachman dan Suryani 2010; UNEP and IWMI dalam Sutrisno dan Heryani 2013). Kenyataan yang terjadi juga menunjukkan, berdasarkan pendapat Direktorat Jendral Prasarana dan Sarana Pertanian (2015), P3A dirasakan belum secara optimal melaksanakan pengelolaan jaringan irigasi tersier. Masalah yang masih dihadapi oleh P3A menurut Darma dan Fudjaja (2011) adalah lahan pertanian anggota P3A masih mengalami kekurangan air, pembagian air yang tidak merata dan tidak sesuai jadwal dari daerah hulu ke hilir akibat kurangnya komunikasi diantara mereka. Penelitian Muchlis (2009) dan Hermann (2011) mendukung hal tersebut. Kebanyakan lembaga atau program yang diinisiasi oleh pemerintah tidak memberikan peluang bagi masyarakat ikut berpartisipasi dalam musyawarah, peluang masyarakat dalam pengambilan keputusan juga tidak ada karena musyawarah selalu didominasi oleh elit desa dan fasilitator. Forum hanya berfungsi untuk memberi "pengumuman".

Keberadaaan P3A menunjukkan bahwa masyarakat seharusnya memiliki akses untuk turut serta mengendalikan pembangunan, yang mana menurut Narayan dan Pritchett (dalam Dasgupta dan Serageldin 2000) pembangunan yang dikendalikan oleh masyarakat merupakan sebuah proses yang diprakarsai dan diatur oleh kelompok masyarakat, dan mereka mengambil aksi untuk kepentingan bersama. Aksi untuk menyelesaikan masalah dihasilkan dari komunikasi partisipatif (Freire 2000; Tufte dan Mefalopulos 2009; Warnock et al. 2007, Klandermans, Goslinga dalam Wijanarko 2014). Penelitian ini menambahkan peubah jaringan komunikasi, baik di dalam masing-masing P3A maupun dengan P3A lain di daerah irigasi (DI) yang sama, untuk mengetahui bagaimana komunikasi yang terjalin antara P3A hulu dan hilir dalam Gabungan Perkumpulan Petani Pengguna Air (GP3A). Kegiatan komunikasi tentunya tidak terlepas dari karakteristik pelaku komunikasinya. Hermann (2011) dan Aminah (2013) mengemukakan proses komunikasi partisipatif berhubungan dengan 
kepemimpinan. Selanjutnya ada variabel pengalaman, umur, norma dalam kelompok dan ukuran kelompok (Aminah 2013; Goldberg dan Larson 2011; Devito 1997). Variabel non jaringan berupa variabel usia, sosial ekonomi, dan status diperlukan untuk melihat perubahan perilaku individu yang dipengaruhi variabel analisis jaringan komunikasi (Rogers dan Kinchaid 1981).

Berdasarkan hal tersebut, penelitian ini bertujuan untuk (1) mengidentifikasi komunikasi partisipatif, jaringan komunikasi dan aksi kolektif yang diterapkan P3A, (2) menganalisis hubungan antara karakteristik kelompok dengan komunikasi partisipatif, (3) menganalisis hubungan antara karakteristik kelompok dengan jaringan komunikasi, (4) menganalisis hubungan antara jaringan komunikasi dengan komunikasi partisipatif, (5) menganalis hubungan antara komunikasi partisipatif dengan aksi kolektif, dan (6) menganalisis hubungan antara jaringan komunikasi dengan aksi kolektif.

\section{TINJAUAN PUSTAKA}

\section{Aksi Kolektif}

Warnock et al. (2007) serta Klandermans, Goslinga dalam Wijanarko (2014) menyatakan bahwa intervensi komunikasi pembangunan dalam collective action pada level komunitas tergantung pada kegiatan komunikasi di dalamnya, yaitu termasuk adanya diskusi, identifikasi masalah dan solusinya, berbagi informasi, negosiasi, persetujuan, bergabung dalam proses pengelolaan, dan proses pertanggungjawaban yang sama dalam komunitas. Interaksi sosial dalam hubungan dengan kapital sosial merupakan bagian yang tidak terlepas dari kegiatan kolektif (Narayan dan Pritchett, Putnam dalam Lawang 2005). Tindakan (sosial), termasuk terlibat dalam aksi kolektif, yang diambil seseorang merupakan hasil keputusan pribadinya untuk melakukan sesuatu. Keputusan untuk bertindak biasanya diambil dengan pertimbangan makna atau nilai yang ada pada seseorang (Weber dalam Lawang 2005).

Informasi juga diproses tidak hanya oleh individu yang terpisah akan tetapi oleh manusia yang saling berinteraksi dengan yang lain dalam lingkaran informal, grup primer dan jaringan pertemanan (Klandermans dan Goslinga dalam Wijanarko 2014). Proses tersebut dipandu oleh norma, nilai, ide-ide di satu pihak dan kondisi situasional di lain pihak, dan diarahkan untuk mencapai suatu tujuan tertentu, dengan cara-cara yang dipertimbangkan subyektif, efektif dan efisien (Parson dalam Lawang 2005).

\section{Komunikasi Partisipatif}

Komunikasi partisipatif adalah suatu dialog terbuka, di mana sumber dan penerima berinteraksi secara kontinyu, memikirkan secara konstruktif situasi, mengidentifikasikan kebutuhan dan permasalahan, memutuskan apa yang dibutuhkan untuk meningkatkan situasi dan bertindak atas situasi tersebut (Nair dan White 2004). Komunikasi partisipatif terdiri dari unsur penting, diantaranya dialog dan aspirasi (Tufte dan Mefalopulos 2009; Freire 2000). Dialog merupakan aktivitas pertukaran makna, infomasi, pengetahuan, dan pengalaman (Nair dan White 2004, Aminah 2013, Rogers and Kincaid 1981, Chitnis 2005, Goldberd dan Larson 2011, Kheerajit dan Flor 2013). Aktivitas ini disertai dengan rasa saling 
percaya antara orang-orang yang terlibat di dalamnya (Freire 2000, Mardikanto 2010), kemudian membentuk ke arah saling pengertian dan persetujuan bersama (Rogers dan Kincaid 1981). Esensis dialog adalah pengakuan dan penghormatan untuk pembicara lain (Rahim 2004).

Sieburg (dalam Larson dan Goldberg 2011) mengembangkan suatu metode untuk mengamati komunikasi kelompok sehubungan dengan apakah tindakan komunikasi para anggota itu bersifat menegaskan (confirming) atau tidak menegaskan (misconfirming) untuk mengindikasikan pengakuan terhadap tindakan komunikasi sebelumnya. Aspirasi berkaitan dengan kesempatan yang diberikan pemerintah atau penyelenggara program pembangunan agar penerima manfaat dapat dengan bebas dan terbuka menyuarakan suara mereka (Tufte dan Mefalopulos 2009, Mardikanto 2010). Aspirasi dalam diskusi dapat dibagi menjadi setuju dengan keadaan tertentu, tidak setuju dengan keadaan tertentu, memberi informasi atau saran, meminta informasi atau saran (Gouran dan Baird, Bales dalam Goldberg dan Larson 2011).

\section{Jaringan Komunikasi}

Jaringan merupakan ikatan antar simpul (orang atau kelompok) yang dihubungkan dengan media berupa hubungan sosial. Jaringan adalah sumber pengetahuan yang menjadi dasar utama dalam pembentukan kepercayaan strategik. Artinya melalui jaringan orang saling tahu, saling menginformasikan, saling mengingatkan dan saling bantu dalam melaksanakan atau mengatasi suatu masalah (Lawang 2005)

Unit analisis individu menurut Monge dan Contractor (2003) dan Lawang (2005) dapat berupa seseorang, kelompok, atau organisasi (institusi) dalam kasus jaringan interorganisasi. Konsep pengukuran yang dapat digunakan untuk menganalisis jaringan untuk kelompok (Eriyanto 2014), diantaranya yaitu ukuran adalah jumlah anggota dalam jaringan, diameter adalah jumlah terjauh di antara dua aktor dalam jaringan dan kepadatan atau densitas yang dikembangkan Scott (2000) dan Prell (2012). Kepadatan menghitung berapa banyak hubungan pertalian yang terdapat dalam jaringan dan mengekspresikan jumlah tersebut sebagai proporsi dari hubungan pertalian potensial dalam jaringan. Semakin kecil ukuran jaringan, semakin kecil diameter, dan semakin tinggi nilai densitas, maka akan semakin padat jaringan, dan dapat dikatakan jaringan akan semakin kohesif.

\section{Karakteristik Kelompok}

Proses komunikasi partisipatif yang rendah dipengaruhi oleh kurangnya pengalaman penerima manfaat dan tidak adanya keterlibatan dan dukungan pemimpin lokal (Hermann 2011). Aminah (2013) menguatkan dengan hasil penelitian bahwa keterlibatan pemimpin, pengalaman berusaha tani, dan umur berpengaruh pada keiikutsertaan petani dalam dialog dan kualitas komunikasi partisipatif. Hampir semua kelompok diskusi mempunyai pemimpin sehingga pemimpin-pemimpin ini haruslah mempunyai kemampuan cara memulai diskusi, menjaga kelangsungan diskusi, memastikan bahwa hanya hal-hal penting saja yang dibahas dan bahwa konflik digunakan secara konstruktif serta menutup 
suatu diskusi (Cortright dan Hinds, Crowell, Howell dan Smith, Kaltner, serta McBurner dan Hance dalam Goldberg dan Larson 2011).

Goldberg dan Larson (2011) juga mengungkapkan bahwa ada ciri-ciri yang hanya dapat diukur pada tingkatan kelompok berkaitan dengan komunikasi yaitu distribusi kepemimpinan dan kemudian norma dalam kelompok. Komunikasi partisipatif tidak akan terlaksana jika tidak ada kelompok, oleh karena itu, ukuran kelompok tidak bisa dilepaskan atas hubungannya terhadap komunikasi yang terjadi dalam kelompok tersebut, diungkapkan juga oleh Devito (1997). Variabel non jaringan berupa variabel usia, sosial ekonomi, dan status diperlukan untuk melihat perubahan perilaku individu yang dipengaruhi variabel analisis jaringan komunikasi (Rogers dan Kinchaid 1981). Gambar 1 menampilkan alur kerangka pikir penelitian lebih jelas.

\section{KERANGKA BERPIKIR DAN HIPOTESIS}

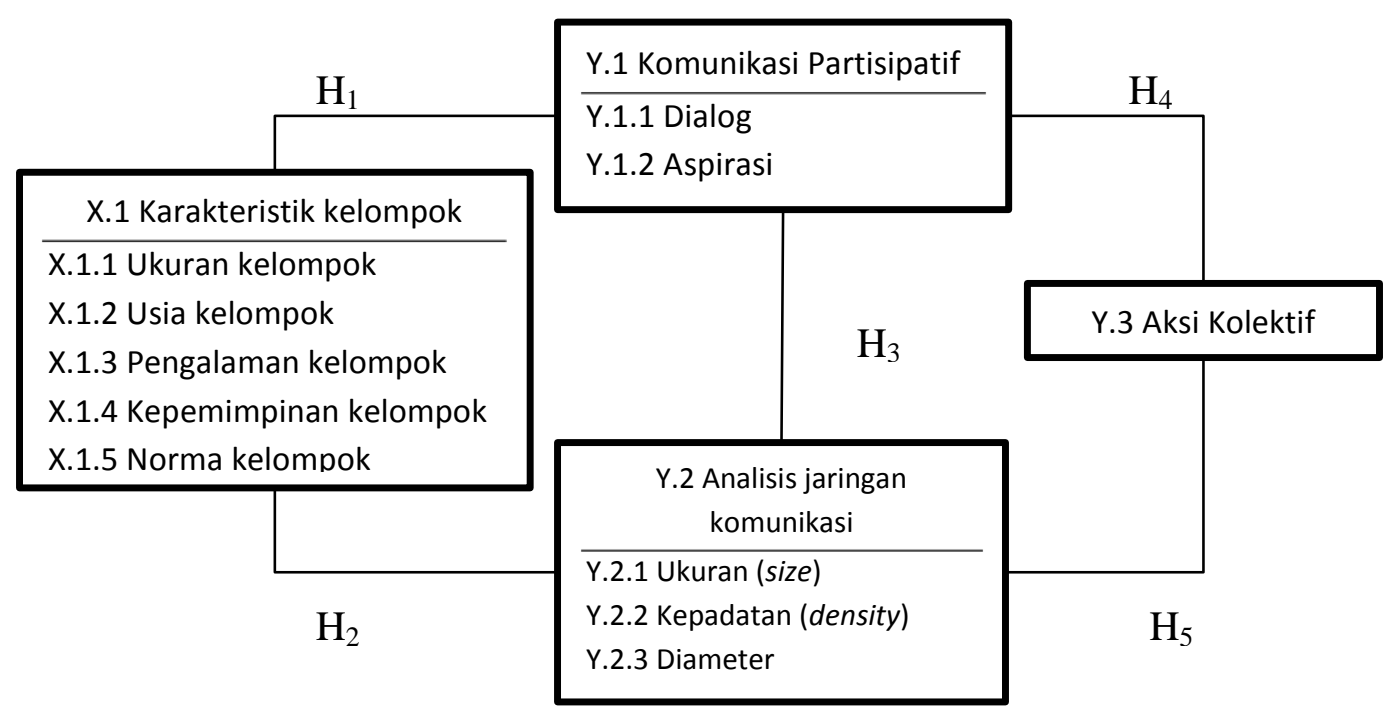

Gambar 1. Kerangka Berpikir

\section{Hipotesis}

Berdasarkan kerangka berpikir pada penelitian ini, maka hipotesis dalam penelitian ini adalah sebagai berikut:

(1) Terdapat hubungan nyata antara karakteristik kelompok dengan komunikasi partisipatif yang terjadi dalam P3A di Daerah Irigasi Papah.

(2) Terdapat hubungan nyata antara karakteristik kelompok dengan jaringan komunikasi P3A di Daerah Irigasi Papah.

(3) Terdapat hubungan nyata antara jaringan komunikasi P3A di Daerah Irigasi Papah dengan komunikasi partisipatif yang terjadi.

(4) Terdapat hubungan nyata antara komunikasi partisipatif dengan aksi kolektif yang terjadi pada P3A di Daerah Irigasi Papah.

(5) Terdapat hubungan nyata antara analisis jaringan komunikasi dengan aksi kolektif pada P3A di Daerah Irigasi Papah. 


\section{METODE PENELITIAN}

Penelitian dilaksanakan pada bulan Maret-April 2016 di Gabungan P3A Papah, berlokasi di tiga kecamatan yaitu Kecamatan Sentolo, Kecamatan Pengasih dan Kecamatan Lendah, Kabupaten Kulon Progo. Penelitian ini menggunakan metode sensus yang bersifat deskriptif korelasional. Jumlah populasi P3A yang berada dalam Gabungan P3A Papah ini sebanyak 17 unit. Pemilihan responden dilakukan secara purposive dan dipilih empat unsur P3A yang dianggap mengetahui seluruh kegiatan P3A berkaitan dengan operasi, pemeliharaan dan pengembangan irigasi yaitu ketua, sekertaris, ulu-ulu dan perwakilan ketua blok. Level analisis jaringan komunikasi adalah sistem dengan desain jaringan utuh (complete network), analisis jaringan komunikasi dilakukan dengan UCINET 6. Analisis hubungan menggunakan Uji Korelasi Rank Spearman (dengan SPSS 16) karena data yang digunakan adalah data ordinal.

\section{HASIL DAN PEMBAHASAN}

\section{Aksi Kolektif dalam GP3A Papah}

Tingkat keikutsertaan dalam aksi kolektif setiap P3A di Gabungan Papah berada pada kategori sedang. Gambar 2 menunjukkan, sebanyak 35,3\% dari tujuh belas P3A di Gabungan Papah memiliki tingkat keiikutsertaan anggota atau perwakilan anggota yang sangat tinggi.

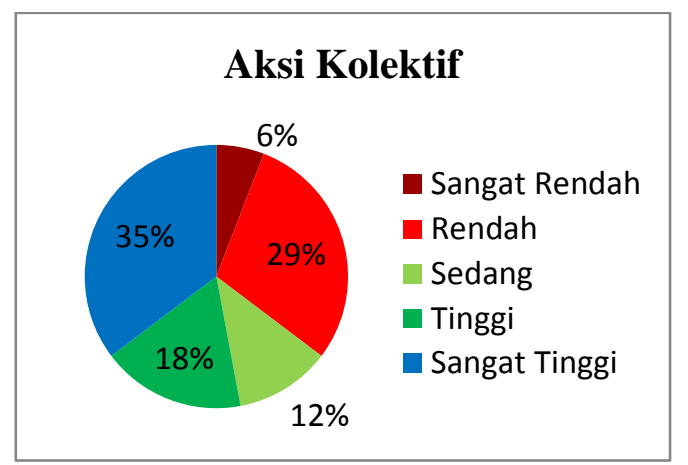

Gambar 2. Persentase Aksi Kolektif GP3A Papah

Anggota dan perwakilan anggota hadir hampir semua atau lebih dari $50 \%$ undangan secara sukarela, karena mereka sangat sadar bahwa kegiatan-kegiatan tersebut untuk kepentingan usaha tani mereka dan mereka merasa butuh air. Hanya ada satu P3A (5,9 persen) yang termasuk dalam kategori sangat rendah. P3A yang termasuk kategori rendah sebanyak lima kelompok (29,4 persen). Pengurus menegaskan bahwa alasan anggota enggan ikut serta dalam aksi kolektif yaitu merasa tanggung jawab mengenai irigasi merupakan kewajiban pengurus P3A saja.

\section{Komunikasi Partisipatif dalam GP3A Papah}

P3A di Gabungan P3A Papah memiliki pertemuan rutin. Mayoritas pertemuan tersebut dilakukan setiap per 35 hari, sering disebut lapanan. Ratarata kemampuan berdialog P3A di Gabungan Papah termasuk pada kategori kemampuan berdialog baik. Kategori cukup baik dan baik merupakan kategori yang memiliki paling banyak P3A, masing-masing sebanyak lima P3A atau 29\% 
(Gambar 3). Total P3A yang termasuk dalam kategori kemampuan berdialog yang sangat buruk dan buruk sebanyak tiga kelompok atau $18 \%$.

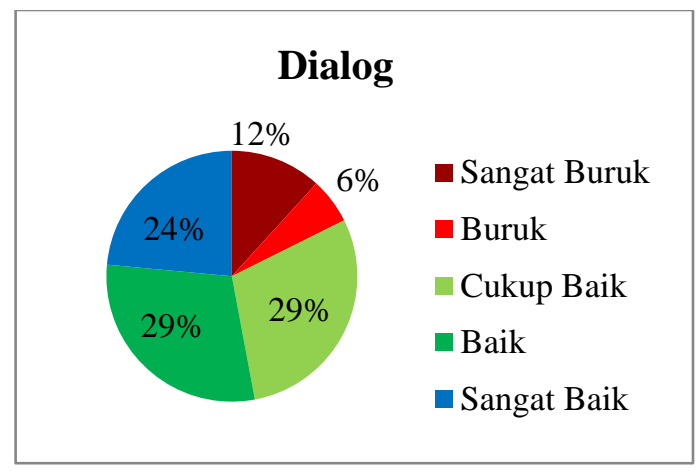

Gambar 3. Persentase Kemampuan Berdialog GP3A Papah

Skor yang rendah berkaitan dengan rendahnya kepercayaan saat berdialog dengan pemerintah, perilaku komunikasi dalam meyampaikan pendapat dalam forum melalui bantuan perantara dan ketidakaktifan bertukar pendapat dengan penyuluh pendamping pertanian saat dialog. Observasi yang dilakukan selama penelitian memperlihatkan penyuluh pendamping jarang muncul dalam diskusi, terutama diskusi rutin masing-masing P3A dan fungsi penyuluh pendamping lebih sebagai pengirim atau mengumumkan pesan. Petani juga memiliki pandangan bahwa penyuluh lebih mengetahui keadaan lapang dimana mereka langsung melakukan praktek pertanian dan irigasi.

Kesempatan mengemukakan aspirasi di P3A Gabungan Papah termasuk dalam kategori tinggi. Gambar 4 memperlihatkan kategori tingkat kesempatan mengemukakan aspirasi yang tinggi mencakup enam P3A atau $35 \%$. Kategori sangat tinggi pada tingkat kesempatan mengemukakan aspirasi mencakup paling banyak P3A yaitu sebanyak delapan P3A (47\%).

Hanya satu kelompok (6\%) yang termasuk dalam tingkat sangat rendah. Diskusi yang terjadi biasanya bersifat informal dan terbuka. Diskusi mengizinkan kepada siapa saja untuk mengemukakan pendapat, saran dan pertanyaan tanpa mendahulukan orang yang berada pada posisi yang lebih tinggi.

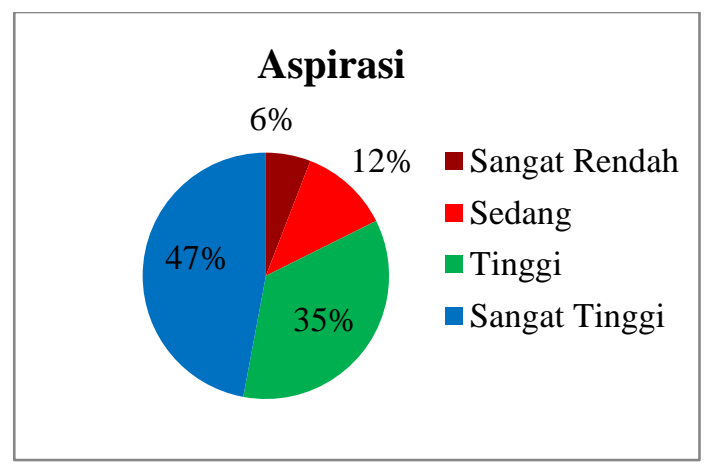

Gambar 4. Persentase Kesempatan Mengemukakan Aspirasi GP3A Papah 


\section{Hubungan Komunikasi Partisipatif dengan Aksi Kolektif $\left(\mathbf{H}_{4}\right)$}

Hasil Uji korelasi menunjukkan komunikasi partisipatif (kemampuan berdialog atau kesempatan mengemukakan aspirasi) tidak memiliki hubungan yang signifikan dengan tingkat keikutsertaan dalam aksi kolektif (Tabel 1). Ratarata P3A di Gabungan P3A Papah memiliki kemampuan berdialog baik dan kesempatan mengemukakan aspirasi yang tinggi, tetapi memiliki tingkat keiikutsertaan sedang dalam aksi kolektif.

Tabel 1. Nilai Koefisien Uji Korelasi Komunikasi Partisipatif dengan Aksi Kolektif

\begin{tabular}{cc}
\hline Komunikasi Partisipatif & Aksi Kolektif \\
\hline Dialog & 0,254 \\
Aspirasi & 0,215 \\
\hline
\end{tabular}

Beberapa P3A dengan tingkat keikutsertaan dalam aksi kolektif didasarkan pada kesadaran mengenai kebutuhan mereka terhadap air untuk usaha pertanian. Beberapa P3A tersebut berada di wilayah yang mengalami kesulitan mendapat pasokan air setiap musim tanam (MT) II dan MT III yaitu Desa Tuksono, Gulurejo, Srikayangan, Demangrejo dan Kedungsari. Curah hujan yang sedikit pada MT II dan III menyebabkan berkurangnya debit air pada daerahdaerah bagian hilir ini. Kondisi jaringan yang baik dibutuhkan agar debit air yang sedikit tidak terhambat atau terbuang akibat adanya sampah, waled dan kerusakan jaringan, sehingga anggota aktif ikut serta dalam aksi kolektif untuk operasi, pemeliharaan dan pembangunan jaringan irigasi. Koutsou et al. (2014) mengemukakan bahwa kerja keras pada aksi kolektif akan menghasilkan fleksibelitas dalam rangka beradaptasi lebih baik terhadap kondisi baru. Selama tidak terjadi perubahan kondisi pada P3A di hulu, maka aksi kolektif rendah ini akan bertahan. Kesulitan akan muncul jika terjadi perubahan kondisi karena mereka tidak terbiasa terlibat dalam aksi kolektif untuk menyelesaikan masalah irigasi di P3Anya, sehingga tidak akan fleksibel dalam beradaptasi.

\section{Jaringan Komunikasi dalam GP3A Papah}

Jaringan secara keseluruhan P3A di Wilayah Papah memiliki ukuran 137, dengan kepadatan jaringan GP3A Papah yaitu 1,4\%. Jaringan ini memiliki kepadatan yang sangat rendah karena anggota tidak saling berinteraksi. Interaksi tidak merata ke semua anggota atau di dominasi aktor tertentu. Hal ini terjadi karena interaksi di tingkat gabungan didominasi oleh para ketua P3A unit atau pengurus P3A unit yang merangkap menjadi pengurus di GP3A. 


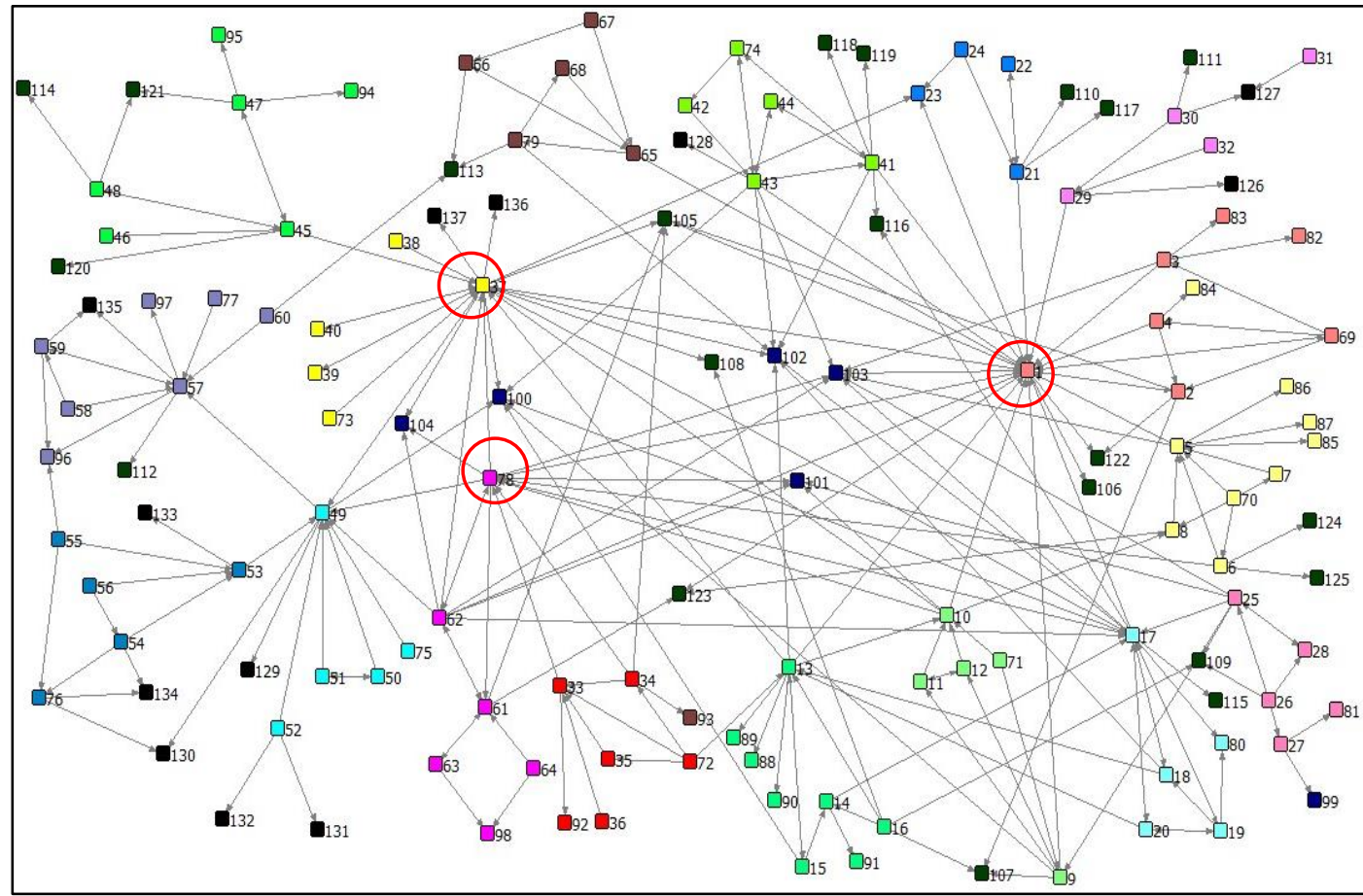

Keterangan: Aktor dikelompokkan berdasarkan warna

Gambar 5. Jaringan Komunikasi Gabungan P3A Papah

Informasi berkaitan dengan pengairan dan P3A biasanya disampaikan secara beruntun, dari dinas-dinas terkait ke ketua atau perwakilan GP3A dalam pertemuan per 15 hari, dari ketua GP3A ke ketua P3A dalam pertemuan rutin setiap tanggal lima dan dari ketua P3A ke anggota P3A melalui rapat rutin P3A.

Gambar 5 menguatkan hal tersebut, nodes yang berada dalam lingkaran merupakan aktor dengan indegree centrality dan outdegree centrality tertinggi dalam jaringan. Dengan kata lain petani pada node tersebut memiliki tingkat kepopuleran yang tinggi, bisa dilihat dari banyaknya link yang menuju dan berasal dari ketiga nodes tersebut. Nodes tersebut adalah aktor nomor 37 (uluulu GP3A), nomor 1 (ketua GP3A) dan nomor 78 (bendahara GP3A). Indegree centrality masing-masing aktor tersebut secara berurutan yaitu 11, 18 dan 6 serta outdegree centrality masing-masing aktor tersebut secara berurutan yaitu 13, 10 dan 9. Ketiga nodes tersebut berperan sebagai gatekeeper bagi informasi yang masuk, mereka selanjutnya terhubung dengan ketua masing-masing P3A unit. Uraian tersebut memperlihatkan bahwa anggota unit P3A jarang yang memiliki akses informasi langsung ke tingkat gabungan, tetapi harus melewati ketua P3A terlebih dahulu. Diameter adalah jarak terjauh di antara dua aktor dalam suatu jaringan (Carolan dalam Eriyanto 2014).

Diameter jaringan GP3A Papah adalah 11, artinya terdapat 11 langkah yang dibutuhkan untuk menghubungkan seseorang dengan anggota lainnya dalam jaringan, sangat jauh untuk ukuran jaringan yang tidak terlalu besar. Hal tersebut disebabkan oleh struktur hierarkis dalam penyebaran informasi seperti yang telah dijelaskan di atas.

P3A yang memiliki ukuran paling besar adalah P3A Wargo Rukun yaitu 28 nodes, sedangkan ukuran paling kecil yaitu tujuh nodes dimiliki oleh P3A Sido 
Makmur (Kedungsari). Sebanyak 47,1 persen P3A di DI Papah memiliki jaringan dengan jumlah nodes di bawah 12. P3A Tani Mulyo merupakan P3A dengan kepadatan tertinggi yaitu 55\% dan P3A Suka Makmur merupakan P3A dengan kepadatan terendah yaitu $13,9 \%$. Kepadatan jaringan sebanyak 47,1 persen P3A di DI Papah berada di antara 22,13\% - 30,34\%. Mayoritas, sebanyak 41,2 persen memiliki diameter dua, artinya dalam jaringan P3A unit masih ada yang berkomunikasi lewat perantara walaupun jaringannya memiliki ukuran kecil.

\section{Hubungan Jaringan Komunikasi dengan Aksi Kolektif (H5) dan Komunikasi Partisipatif (H3)}

Salah satu hipotesis penelitian ini adalah adanya hubungan nyata antara jaringan komunikasi dengan aksi kolektif. Keputusan untuk bekerja sama atau tidak dengan yang lain dalam mencapai tujuan bersama tidak terjadi secara bebas tetapi dengan konteks muncul hubungan sosial terlebih dulu, jaringan dan intitusi (Robbin et al.; Ostrom and Ahn dalam Bisung et al. 2014). Jaringan ditandai dengan perkenalan dan interaksi, aksi kolektif lebih maju karena sinergi keduanya mengambil alih dalam mencapai tujuan bersama (Koutsou et al. 2014). Tabel 2 menunjukkan hasil uji korelasi rank Spearman menampilkan hasil bahwa kepadatan jaringan berhubungan nyata negatif dengan aksi kolektif. Artinya, semakin padat jaringan (interaksi anggota kelompok merata) maka tingkat keikutsertaan anggota kelompok dalam aksi kolektif semakin rendah.

Hasil penelitian ini didukung oleh pendapat Ohet et al. (dalam Bodin and Crona 2009) bahwa terdapat bukti bahwa efek positif dari kepadatan jaringan dalam pengelolaan sumber daya alam tidak selalu terus meningkat tetapi mungkin pada kenyataannya menurun pada kepadatan tinggi. Kepadatan pertalian yang sangat tinggi dapat, pada kenyataannya, mengurangi efektivitas sebuah kelompok dalam aksi kolektif. Kepadatan jaringan sangat tinggi dapat menyebabkan homogenisasi informasi dan pengetahuan yang menghasilkan kurang efisien penggunaan sumber daya dan/atau mengurangi kapasitas untuk beradaptasi dengan perubahan kondisi (Bodin dan Norberg; Little dan McDonald; Ruef dalam Bodin dan Crona 2009).

Tabel 2. Koefisien Uji Korelasi Jaringan Komunikasi dengan Aksi Kolektif

\begin{tabular}{llll}
\hline \multirow{2}{*}{ Jaringan Komunikasi } & \multirow{2}{*}{ Aksi Kolektif } & \multicolumn{2}{c}{ Komunikasi Partisipatif } \\
\cline { 3 - 4 } & & Dialog & Aspirasi \\
\hline Ukuran & $-0,106$ & 0,023 & $-0,203$ \\
Kepadatan & $\mathbf{- 0 , 5 5 2 *}$ & $-0,052$ & $-0,107$ \\
Diameter & $-0,064$ & $-0,018$ & $-0,243$ \\
\hline
\end{tabular}

Keterangan: * berhubungan nyata ( $p$-value $<0.05$ )

Berdasarkan uji korelasi rank Spearman diketahui bahwa tidak terdapat indikator jaringan komunikasi yang berhubungan nyata dengan indikator komunikasi partisipatif. Carolan (dalam Eriyanto 2014) menyatakan bahwa struktur relasi di antara aktor akan berbeda antara jaringan dengan ukuran kecil dan besar. Intensitas komunikasi dari jaringan ukuran kecil pasti lebih sering dibandingkan dengan jaringan dengan ukuran besar. Begitu pula kepadatan yang 
tinggi akan memungkinkan interaksi yang lebih sering. Diameter adalah jarak terjauh di antara dua aktor dalam suatu jaringan (Carolan dalam Eriyanto 2014).

Diameter yang lebih pendek juga akan memudahkan interaksi karena jarak aktor untuk berinteraksi satu sama lain menjadi lebih dekat. Kenyataannya intensitas hampir seluruh P3A sama dalam berkomunikasi (berdialog) yaitu sekali dalam satu bulan, sehingga besar atau kecil ukuran, kepadatan dan diameter jaringan P3A tidak berhubungan dengan kemampuan berdialog dan kesempatan menemukan aspirasi.

\section{Karakteristik Kelompok dalam GP3A Papah}

Sebanyak enam belas P3A di Gabungan P3A Papah berumur lebih dari sama dengan dua puluh tahun, artinya hampir semua P3A di Papah sudah mencapai tahap kematangan dalam berorganisasi. Hanya satu organisasi yang baru berdiri dua tahun yaitu P3A Sido Makmur di Desa Kedungsari, Kecamatan Pengasih. Rata-rata jumlah anggota yang hadir dalam pertemuan rutin di tiap P3A berada pada kategori cukup banyak, sekitar dua puluh orang. Jumlah P3A terbanyak termasuk dalam kategori di bawah lima belas orang, yaitu enam kelompok $(35,3 \%)$. Kategori di atas 25 orang hanya mencakup empat kelompok atau 23,5\%. Kategori yang sangat banyak tidak hanya dihadiri oleh pengurus inti dan pengurus teknis saja, namun seringkali disatukan dengan kelompok tani setempat.

Mayoritas kelompok P3A di wilayah Daerah Irigasi Papah yaitu sebanyak delapan P3A $(47,1 \%)$ memiliki pengalaman yang tinggi. P3A dengan pengalaman yang sangat rendah terdiri dari empat P3A (23,5\%). Nilai rata-rata dari pengalaman P3A di wilayah DI Papah secara keseluruhan termasuk pada kategori pengalaman sedang. Tingkat kepemimpinan dalam dialog di Gabungan P3A Papah termasuk dalam kategori sedang, artinya dalam menjalankan peranan kepemimpinan dalam diskusi, para pemimpin yang biasanya adalah ketua P3A tidak selalu memegang kontrol sendiri. Ketua masing-masing P3A mendistribusikan kontrol pada saat diskusi, contohnya pada saat memulai diskusi biasanya dilakukan oleh sekretaris. Tingkat keberadaan norma rata-rata P3A di wilayah Daerah Irigasi Papah yaitu 10.37, termasuk dalam kategori tinggi (berada pada selang 10,06-10,40). Tingkat keberadaan norma dengan kategori sangat rendah terdiri dari dua (11,8 persen) P3A.

\section{Hubungan Karakteristik kelompok dengan Komunikasi Partisipatif $\left(\mathrm{H}_{1}\right)$ dan Jaringan Komunikasi $\left(\mathbf{H}_{2}\right)$}

Hipotesis selanjutnya yaitu terdapat hubungan nyata antara komunikasi partisipatif dengan karakteristik P3A. Tabel 3 memperlihatkan hasil uji korelasi rank Spearman diketahui bahwa terdapat dua indikator karakteristik kelompok, yaitu umur dan pengalaman, yang berhubungan nyata dengan indikator komunikasi partisipatif. Penelitian terdahulu juga menemukan hubungan nyata antara pengalaman dan komunikasi partisipatif (Saputra 2011; Mulyasari 2009). 
Tabel 3. Nilai Koefisien Uji Korelasi Karakteristik P3A dengan Komunikasi Partisipatif dan Jaringan Komunikasi

\begin{tabular}{lccccc}
\hline Variabel Komunikasi & \multicolumn{5}{c}{ Karakteristik P3A } \\
\cline { 2 - 6 } & Umur & Ukuran & Kepemimpinan & Pengalaman & Norma \\
\hline Komunikasi Partisipatif & & & & & \\
$\quad$ Dialog & $\mathbf{0 . 5 6 6 *}$ & -0.001 & 0.322 & $\mathbf{0 . 4 8 5 *}$ & 0.059 \\
$\quad$ Aspirasi & 0.116 & -0.034 & -0.009 & 0.345 & -0.080 \\
Jaringan Komunikasi & & & & & \\
$\quad$ Ukuran & $-0,094$ & 0,126 & $-0,227$ & $\mathbf{0 , 5 1 2 *}$ & 0,241 \\
$\quad$ Kepadatan & 0,025 & 0,090 & $-0,248$ & 0,224 & $-0,012$ \\
$\quad$ Diameter & $-0,109$ & 0,337 & $-0,007$ & 0,025 & 0,287 \\
\hline
\end{tabular}

Keterangan: * berhubungan nyata ( $p$-value $<0.05)$

Semakin lama P3A berdiri beiringan dengan semakin meningkatnya pengalaman P3A tersebut dalam menjalankan seluruh aktivitasnya, tentunya termasuk di dalamnya aktivitas komunikasi yang dikelola semakin baik dari waktu ke waktu. Wahyuningsih dan Tanggulungan (2014) menegaskan bahwa organisasi yang mampu bertahan dalam jangka panjang adalah organisasi yang telah berpengalaman dalam mengelola aktivitasnya. Saputra (2011) menegaskan bahwa pengalaman menyelesaikan masalah dalam kelompok dan dalam proses pemeliharaan kelompok dengan dialog serta pengalaman refleksi-aksi, akan menuntun pada perilaku komunikasi, yaitu dapat memberi dan menerima sumbangan ide yang berbeda dari anggota kelompok serta dapat menciptakan situasi hangat dalam dialog. Mulyasari (2009) menyatakan kemampuan (pendidikan, pengalaman dan modal) yang rendah mengakibatkan rendahnya kemauan untuk berpartisipasi dan berujung pada tidak adanya kepercayaan dan keberanian untuk memberikan pertanyaan, masukan atau pendapat.

Kepemimpinan kelompok tidak berhubungan nyata, dikarenakan baik kepemimpinan tinggi atau rendah, komunikasi yang terjadi tetap berjalan baik. Walaupun kemampuan berdialog baik dan terdapat kesempatan beraspirasi tetapi terdapat bukti bahwa pemimpin merupakan aktor yang sangat krusial dalam menentukan apakah diskusi rutin berjalan dengan baik atau tidak. P3A unit terlalu bergantung pada ketua mereka sehingga saat ketua tidak aktif maka diskusi rutin tersebut juga akan berhenti. Hal ini sejalan dengan penemuan Onabaju dalam Hermann (2011) bahwa kolaborasi dengan dan bergantung pada kepemimpinan formal untuk mengimplementasikan aktifitas komunikasi pembangunan partisipatif berarti kerugian akan timbul saat posisi berubah.

Ukuran tidak berhubungan nyata karena besar atau kecil ukuran ditentukan oleh komposisi kepengurusan dan perwakilan anggota, semakin banyak blok maka akan semakin besar ukuran. Artinya, informasi, ide, saran atau pertanyaan tetap akan disampaikan oleh perwakilan masing-masing posisi. Norma yang berlaku juga hanya berupa teguran sehingga tidak terlalu mempengaruhi jalannya dialog dan kesempatan beraspirasi.

Hasil uji korelasi rank Spearman memperlihatkan terdapat indikator karakteristik kelompok yang berhubungan nyata positif dengan indikator jaringan komunikasi P3A, yaitu pengalaman. Semakin tinggi pengalaman P3A 
maka semakin besar juga ukuran (jumlah link) jaringan. Pengalaman mencakup pada keikutsertaan lomba P3A dan penerimaan kunjungan studi banding, kedua kegiatan tersebut tentunya akan memberi kesempatan untuk P3A yang mengikuti kegiatan tersebut untuk membangun relasi baru. Umur kelompok, jumlah anggota dalam diskusi, kepemimpinan dalam diskusi dan norma dalam kelompok tidak mempengaruhi pada siapa responden menjalin relasi dalam mendiskusikan permasalahan pengairan yang terjadi.

Seluruh P3A berada di lingkungan dimana kepercayaan satu sama lain dan toleransi melekat dalam masyarakat. Menurut Koutsou et al. (2014), dalam masyarakat di mana kepercayaan melekat dan tersebar luas, jaringan informal yang besar dibangun, mempertahankan ikatan yang longgar dan link antara anggota, tanpa ada komitmen yang mengikat. Lebih lanjut Coleman (dalam Eriyanto 2014) mengatakan bahwa jaringan tertutup (adanya link antara nodes) lebih memungkinkan anggota jaringan untuk mematuhi norma yang berlaku karena takut, misalnya dikucilkan oleh yang lainnya. Kenyataannya dalam kasus ini, tertutup atau tidak jaringan, norma berada pada kategori tinggi dalam masalah pengairan. Walaupun sanksinya hanya berupa teguran, tetapi tidak perlu jaringan yang tertutup untuk membuat seseorang dalam jaringan ini merasa malu dengan lingkungan sekitar bila melakukan kesalahan.

\section{SIMPULAN DAN SARAN}

Suasana kekeluargaan dan toleransi yang tinggi dalam kehidupan bermasyarakat menghasilkan kemampuan berdialog dan kesempatan mengemukakan pendapat yang baik, sehingga P3A dapat segera bertindak bila ada permasalah dalam pelayanan irigasi. Dalam diskusi di luar pertemuan rutin, para pengurus hanya menghubungi orang tertentu yang dianggap memiliki informasi terbaru mengenai pengairan, intensitas antar anggota dalam berinteraksi tidak merata karena interaksi didominasi oleh ketua P3A. Kehadiran anggota dalam setiap kegiatan pemeliharaan jaringan irigasi berada di atas lima puluh persen dari jumlah anggota, khususnya pada P3A yang berada di hilir.

Semakin lama P3A berdiri dan semakin tingginya pengalaman P3A dalam mengikuti kegiatan mengenai irigasi, kemampuan P3A semakin meningkat dalam mengelola aktivitas komunikasinya. Pengalaman P3A juga memfasilitasi P3A untuk membangun relasi baru dengan berbagai stakeholders yang baru ditemui, terutama pada kegiatan lomba dan studi banding. Walaupun ketua P3A mendominasi dalam komunikasi di luar diskusi rutin, tetapi dialog dan kesempatan beraspirasi akan tetap dimediasi dalam pertemuan rutin per 35 hari yang disebut lapanan.

Keikutsertaan dalam aksi kolektif P3A disebabkan oleh faktor kebutuhan, sehingga tidak berhubungan dengan peubah komunikasi partisipatif. Kepadatan jaringan yang terlalu tinggi berhubungan dengan menurunnya aksi kolektif, karena P3A menjadi tertutup dari informasi yang berasal dari luar jaringan.

Untuk mencapai komunikasi partisipatif dan aksi kolektif dalam tubuh P3A guna menghadapi tantangan swasembada pangan dan anomali iklim, peneliti memberikan saran kepada berbagai pihak terkait, yaitu: 
(1) Kemampuan berdialog masih perlu ditingkatkan dengan meningkatkan kepercayaan di antara anggota P3A dengan entitas pemerintah terutama penyuluh pertanian. Sebaiknya penyuluh pertanian tidak hanya berfungsi sebagai sender tetapi ikut serta dalam proses dialog dan membantu mencari solusi bila terjadi masalah.

(2) Penting diadakan pelatihan untuk meningkatkan kemampuan komunikasi agar anggota memiliki pengalaman terbiasa berada di dalam forum dan tidak malu lagi untuk menyampaikan pendapatnya secara langsung.

(3) Tingkatkan kegiatan berkaitan mengenai pengairan agar tercipta relasi baru dengan berbagai stakeholders, agar jaringan tetap terbuka pada inovasi dan informasi baru dari luar sehingga tidak akan tertinggal dan kesulitan untuk beradaptasi jika menghadapi kondisi baru.

\section{DAFTAR PUSTAKA}

Aminah S. 2013. Model komunikasi partisipatif untuk keberdayaan petani kecil dalam mewujudkan ketahanan pangan di Kabupaten Halmahera Barat [tesis]. Bogor (ID): Institut Pertanian Bogor.

Bessete G. 2004. Involving the community: Aguide to participatory development communication. Penang: Southbond and International Development Research Centre.

Bisung E, Elliot SJ, Schuster-Wallace CJ, Karanja DM, Bernard A. 2014. Social Capital, Collective Action and Access to Water in Rural Kenya. Social Science \& Medicine, 119(2014): 147-154.

Bodin O, Crona BI. 2009. The Role of Social Networks in Natural Resource Governance: What relational patterns make a difference? Global Environmental Change, 19(3) 366-374.

Darma R, Fudjaja L. 2011. Penguatan P3A untuk pengelolaan IPAIR dan pemeliharaan saluran irigasi di Kabupaten Pinrang. Jurnal Agrisistem. 7(1): 21-36.

Dasgupta P, Serageldin I. 2000. Social capital: a multifaceted perspective. Washington, D.C. (US): The World Bank.

Devito JA. 1997. Komunikasi antar manusia. Jakarta (ID): Professional Books.

Direktorat Jendral Prasarana dan Sarana Pertanian. 2015. Pedoman teknis pengembangan jaringan irigasi APBN-perubahan TA. 2015. Jakarta (ID): Kementrian Pertanian.

Eriyanto. 2014. Analisis jaringan komunikasi: strategi baru dalam penelitian ilmu komunikasi dan ilmu sosial lainnya. Jakarta (ID): Prenadamedia Group.

Freire P. 2000. Pendidikan Kaum Tertindas. Danajaya O, Faqih M, Topatimasang R, Asshiddiqie J, penerjemah: Ahmad I, editor. Jakarta (ID): LP3ES. Terjemahan dari: Pedagogy Of The Opresses.

Goldberg AA, Larson CE. 2011. Komunikasi kelompok proses-proses diskusi dan penerapannya. Jakarta (ID): Penerbit Universitas Jakarta. 
Hermann B. 2011. Crucial factors in the implementation of participatory development communication in Papua New Guinea. DWU Research Journal, 15(1): 115-133.

Koutsou S, Partalidou M, Ragkos A. 2014. Young farmers' social capital in Greece: trust levels and collective action. Journal of Rural Studies. 34(2014): 204211.

Lawang RMZ. 2005. Kapital sosial dalam perspektif sosiologik. Depok (ID): FISIP UI PRESS.

Muchlis F. 2009. Analisis komunikasi partisipatif dalam program pemberdayaan mayarakat (studi kasus pada implementasi musyawarah dalam PNPM Mandiri Perkotaan di Desa Teluk Kecamatan Pemayung Kabupaten Batang Hari) [tesis]. Bogor (ID): Institut Pertanian Bogor.

Mulyasari G. 2009. Komunikasi partisipatif warga pada Bengkulu Regional Development Project [tesis]. Bogor (ID): Institut Pertanian Bogor.

Prell C. 2012. Social network analysis. Singapore (SG): Sage Publication.

Rachman HPS, Suryani E. 2010. Dampak krisis pangan-energi-finansial (PEF) terhadap kinerja ketahahan pangan nasional. Forum Penelitian Agro Ekonomi [Internet]. [diunduh 2014 Des 26]; 28(2): 107-121. Tersedia pada: pse.litbang.deptan.go.id.

Rahim SA. 2004. Participatory development communication as a dialogical process. In White SA, Nair KS. Participatory communication: working for change and development. New Delhi (IND): Sage Publications.

Rogers EM, Kinchaid. 1981. Communication network analysis toward a new paradigm for research. New York (US): The Free Press.

Saputra Y. 2011. Faktor-faktor yang berhubungan dengan perilaku komunikasi partisipatif fasilitator: kasus PNPM Mandiri di Kota Bandar Lampung [tesis]. Bogor (ID): Institut Pertanian Bogor.

Sutrisno N, Heryani N. 2013. Teknologi Konservasi Tanah dan Air untuk Mencegah Degradasi Lahan Pertanian Berlereng. Jurnal Litbang Pertanian, 32(3): 122-13.

Tufte T, Mefalopulos P. 2009. Participatory communication a practical guide. Washington DC (US) : The World Bank.

Wahyuningsih K, Tanggulungan G. 2014. Pengaruh reputasi dan ukuran organisasi terhadap kinerja organisasi nirlaba di Indonesia. Seminar Nasional dan Call for Paper (Sancall 2014): Research Methods And Organizational Studies. ISBN 978-602-70429-1-9: (397-407).

Warnock K, Schoemaker E, Wilson M. 2007. The case for communication. London (GB): Panos.

Wijanarko. 2014. Komunikasi Penyadaran Kritis Gerakan Petani. Makara HubsAsia, 18 (1): 1-14. 